\title{
Review Article \\ Role of Ketamine in Acute Postoperative Pain Management: A Narrative Review
}

\author{
Brian M. Radvansky, Khushbu Shah, Anant Parikh, Anthony N. Sifonios, \\ Vanny Le, and Jean D. Eloy
}

Department of Anesthesiology and Peri-Operative Medicine, Rutgers-New Jersey Medical School, 185 South Orange Avenue, South Orange, Newark, NJ 07103, USA

Correspondence should be addressed to Jean D. Eloy; eloyje@njms.rutgers.edu

Received 16 December 2014; Accepted 16 March 2015

Academic Editor: Kok Eng Khor

Copyright (C) 2015 Brian M. Radvansky et al. This is an open access article distributed under the Creative Commons Attribution License, which permits unrestricted use, distribution, and reproduction in any medium, provided the original work is properly cited.

\begin{abstract}
Objectives. The objective of this narrative review was to examine the usage of ketamine as a postoperative analgesic agent across a wide variety of surgeries. Design. A literature search was performed using the phrases "ketamine" and "postoperative pain." The authors analyzed the studies that involved testing ketamine's effectiveness at controlling postoperative pain. Effectiveness was assessed through various outcomes such as the amount of opiate consumption, visual analog scale (VAS) pain scores, and persistent postoperative pain at long-term follow-up. Results. While many different administration protocols were evaluated, delivering ketamine both as a pre- or perioperative bolus and postoperative infusion for up to 48 hours appeared to be the most effective. These effects are dose-dependent. However, a number of studies analyzed showed no benefit in using ketamine versus placebo for controlling postoperative pain. While ketamine is a safe and well-tolerated drug, it does have adverse effects, and there are concerns for possible neurotoxicity and effects on memory. Conclusions. In a number of limited situations, ketamine has shown some efficacy in controlling postoperative pain and decreasing opioid consumption. More randomized controlled trials are necessary to determine the surgical procedures and administrations (i.e., intravenous, epidural) that ketamine is best suited for.
\end{abstract}

\section{Introduction}

Postoperative pain is one of the most undesirable experiences for a patient undergoing surgery. Deliberate action should be taken to prophylactically treat the pain. If postoperative pain does develop, it should be managed early and aggressively, because severe pain not only induces a delay in discharge and poorer patient satisfaction, but also can create a hyperalgesic condition known as persistent postoperative pain (PPP). This strains not only the patient, but also the healthcare system as a whole. Recent studies show that PPP has an incidence as high as $40 \%$. Furthermore, $18.3 \%$ of patients report that this pain is moderate to severe [1]. Therefore, it is in the anesthesiologist's best interest to be aware of the severity of this problem and of all the pharmacological agents used to prevent and treat postoperative pain. To date, the mainstay of treatment has been the administration of exogenous opioids such as morphine or fentanyl. However, pain is not always fully relieved by such agents, and often patients develop tolerance to them. The ever-increasing doses of opioids are clearly not without their adverse effects. In addition to that, many patients and even some clinicians wrongly believe that addiction can be inevitable after administration of opioids [2].

Recently, interest has focused on the use of N-methyl-Daspartate (NMDA) receptor antagonists for the management of postoperative pain. In particular, ketamine has been thrust into the limelight both as a standalone drug and as an adjuvant to other analgesics (e.g., morphine, fentanyl, and tramadol) [3]. Ketamine exerts its main analgesic effect by antagonism of NMDA receptors [4]. In doing so, ketamine modulates central sensory processing of pain. In both animal and human studies, ketamine has shown itself to be a potent antihyperalgesic agent. It can counteract opioid-induced hyperalgesia and prevent the development of opioid tolerance [4].

Ketamine was first described in the literature in 1965 [5] and FDA-approved in 1970 [6]. The drug was originally 
noticed to have anesthetic effects, much like its close relative, phencyclidine, and only later, its analgesic properties did become coveted [7]. Various studies mentioned throughout this review speak of its use for postoperative analgesia. Ketamine has also been used to treat depression $[8,9]$, complex regional pain syndrome [10], cancer pain [11, 12], alcohol addiction [13], heroin addiction [14, 15], asthma exacerbations [16], wheezing [17], and pain during propofol injection [18]. Adverse effects can include irritability, nightmares, dissociation, headaches, impaired memory, transient elevations in blood pressure and heart rate, urinary tract symptoms, and hepatotoxicity [19].

This review will describe the pharmacology of ketamine, examine its usage as a postoperative analgesic, and discuss its adverse effects and safety profile.

\section{Chemical and Structural Characteristics}

The word "ketamine" is a portmanteau of the words "ketone" and "amine," speaking of its chemical structure. It is a hydrochloride salt, available in both powdered and aqueous forms, with the molecular formula $\mathrm{C}_{13} \mathrm{H}_{16} \mathrm{ClNO}$ and a molecular mass of $237.725 \mathrm{~g} / \mathrm{mol}$. It is composed of a chlorophenyl ring structure that is bonded to a cyclohexanone ring. Ketamine has a chiral center at the carbon-2 atom of its cyclohexanone ring and therefore it exists as the optical stereoisomers $\mathrm{S}(+)$ and $\mathrm{R}(-)$ ketamine. Ketamine was previously only available as a racemic mixture but now comes in its two stereoisomer varieties. S(+)ketamine binds NMDA receptors with affinity that is four times greater than that of $\mathrm{R}(-)$ ketamine. While the duration of $\mathrm{S}(+)$ ketamine is shorter than that of $\mathrm{R}(-)$ ketamine, $\mathrm{S}(+)$ ketamine has been shown to have an analgesic potency twice as great as the racemic mixture and four times as great as $\mathrm{R}(-)$ ketamine [20].

\section{Pharmacodynamics}

The diverse effects and multifaceted mechanisms of action of ketamine have given it the title "nightmare of the pharmacologist" [7]. As there are many high-quality reviews that focus solely on the pharmacology of ketamine [7, 21-23], we will only touch upon the most salient and novel points. Ketamine's predominant effect is NMDA receptor antagonism. It binds noncompetitively to the phencyclidine binding site of NMDA receptors and modifies receptors via allosteric mechanisms. The NMDA receptor is noteworthy in anesthesia because of its role in central sensitization. This complex process involves a nociceptive signal that is potentiated in the peripheral nervous system, causing hyperexcitability in the spinal cord. It can evoke chronic pain and allodynia at surgical incision sites, as well as at sites surrounding incisions. The blunting of central sensitization has played an important role in the prevention and treatment of both postoperative pain and chronic pain [24]. Ketamine has also been used in IV regional anesthesia, further speaking of its peripheral analgesic effects. However, when used as an effective IV regional agent, the concentrations of ketamine were more than 10-fold greater than when used systemically, decreasing the likelihood that systemic administration provides a strong effect on peripheral receptors [25].

Ketamine causes the central effect of anesthesia when it interacts with NMDA receptors in the brain. Brain concentrations of ketamine were directly related to analgesia using an ischemic pain model. Pain activation in the secondary somatosensory cortex, insula, thalamus, and anterior cingulate cortex was all decreased. Functional magnetic resonance imaging (fMRI) studies demonstrated that both pain and ketamine changed brain connectivity in areas involved in endogenous pain modulation. The studies showed that ketamine was responsible for a decrease in connectivity in the brain regions responsible for pain sensing and affective processing $[26,27]$.

The analgesic effects of ketamine do not end with NMDA receptors. It has been shown to interact with opioid receptors $\mu$ preferentially in rats [28]. Studies in guinea pig ileum pointed to possible activation of the $\kappa$-opioid receptor as the site of analgesia [29]. However, subsequent tests performed with naloxone failed to affect the analgesia attributed to the ketamine, and interaction with any opiate receptor was questioned [30]. Other studies showed the reduction in efficacy of ketamine as an anesthetic induction agent in the presence of naloxone, again implying an interaction with the opiate receptor [31]. A 2014 study by Pacheco et al. which used specific opioid receptor blocking agents suggests that interaction with $\mu$ - and $\delta$-opioid receptors is responsible for the central antinociceptive effects of ketamine [32].

Studies show that prevention of opioid tolerance may be another mechanism of pain prevention by ketamine. It has been reported that $\mu$-receptor activation by opioids leads to a sustained increase in glutamate synaptic effectiveness at the level of NMDA receptors. Although the mechanisms that allow ketamine to be an analgesic and opiate-sparing agent after opiate exposure remain poorly understood; an important concept that is worth mentioning is being studied in rat models. Rat studies in brain ischemia have found a role of postsynaptic density (PSD), proteins, specifically PSD95, in potentiating NMDA function and signaling to nitric oxide synthase resulting in chronic and neuropathic pain. Studies show that ketamine may decrease injury-triggered increases in interactions between the NMDA receptor, postsynaptic density protein 95 (PSD95), and protein kinases, thereby reducing nitric oxide-related neuronal injury [33]. This concept may represent a mechanism underlying reduced pain sensitization and opiate tolerance phenomena. Cancer patients who receive chronic opioids often have developed a high level of tolerance, and, in this situation, ketamine can be a useful adjuvant in analgesia [34, 35].

Many other receptors have been shown to play role in ketamine analgesia; however, their mechanisms remain unclear. Once thought to be an opioid receptor, the sigma-receptor has been implicated as a binding site for ketamine. The role of sigma receptors is uncertain; they may modify other receptors such as NMDA receptors.

Needless to say, the effects of ketamine on the human body, both within the realm of analgesia and without, are incredibly complex. Further study is encouraged to fully 
elucidate the effects of this multifaceted drug on the body's various receptors.

\section{Applications in Acute Pain Management}

4.1. Otolaryngologic Surgery. A 2013 study by Jha et al. [36] (Table 1) evaluated the efficacy of ketamine in postoperative analgesia after surgical site infiltration for pediatric patients undergoing cleft palate surgery. Surgical sites were infiltrated with either $2 \mathrm{mg} / \mathrm{kg}$ of bupivacaine or $0.5 \mathrm{mg} / \mathrm{kg}$ of ketamine. Although pain scores were similar between groups at the $12 \mathrm{~h}$ mark, pain scores were lower with ketamine at the $24 \mathrm{~h}$ mark. Only $28 \%$ of children in the ketamine group required rescue analgesia, compared to $64 \%$ in the bupivacaine group. Administration of ketamine also led to statistically significant decreases in sleep disturbances and dysphagia when compared to the bupivacaine group. This allowed for an earlier resumption of feeding with ketamine infiltration.

Eghbal et al. [37] examined the effects of ketamine on postoperative pain and emergence agitation in children undergoing adenotonsillectomy. This randomized clinical trial (RCT) divided children into a placebo (normal saline) group and a ketamine $(0.25 \mathrm{mg} / \mathrm{kg}$ IV) group. Emergence agitation scores, acetaminophen requirements, and pain scores at all hours were significantly lower in the ketamine group.

A 2014 meta-analysis by Cho et al. [38] reports that, in tonsillectomy in children, preoperative administration of ketamine, either systemically or locally, resulted in significantly decreased pain at 4 hours and decreased analgesic need over 24 hours.

4.2. Spinal Surgery. Nitta et al. [39] tested the efficacy of morphine alone, morphine and ketamine, morphine and clonidine, and morphine/ketamine/clonidine in reducing the need for patient-controlled analgesia (PCA) following cervical and lumbar spinal surgery. When used, ketamine was delivered as a high-dose infusion at $2.0 \mathrm{mg} / \mathrm{kg} /$ hour. The study demonstrated that oral premedication with clonidine combined with intraoperative administration of ketamine potentiated the analgesic effect of postoperative IV morphine. There was a significant reduction in the amount of PCA requests and in the amount of cumulative morphine delivered via PCA at 24, 36, 48, and 60 hours. This demonstrates ketamine's adjunctive effect when added to other analgesics, synergistically decreasing overall administration of opioids.

Hadi et al. [40] used low-dose IV ketamine as an adjunct to therapy during and after lumbar microdiscectomy surgery. Patients were divided into a control group, a group receiving $1 \mu \mathrm{g} / \mathrm{kg} / \mathrm{min}$ perioperatively and a group receiving both $1 \mu \mathrm{g} / \mathrm{kg} / \mathrm{min}$ perioperatively and $1 \mu \mathrm{g} / \mathrm{kg} / \mathrm{min}$ postoperatively. The patients in the control group required first analgesic demand dose earlier than the ketamine groups. Total morphine consumption, visual analog scale (VAS) pain scores, and rates of nausea and vomiting were significantly lower in the group receiving both peri- and postoperative ketamine versus the control group.

Kim et al. [41] report similar results in lumbar spinal fusion patients: a ketamine $2 \mu \mathrm{g} / \mathrm{kg} / \mathrm{min}$ infusion following a bolus dose of $0.5 \mathrm{mg} / \mathrm{kg}$ resulted in patients requiring significantly less fentanyl in the postoperative period with no increase in adverse effects [41].

Pestieau et al. [42] evaluated a low-dose perioperative infusion of ketamine in pediatric patients undergoing scoliosis surgery, a procedure in which opioid analgesic requirements are routinely high. The study was a double-blinded controlled trial with one group receiving ketamine and the other receiving a placebo. Patients were given a bolus of $0.5 \mathrm{mg} / \mathrm{kg}$ ketamine prior to incision, an intraoperative infusion of $0.25 \mathrm{mg} / \mathrm{kg} / \mathrm{h}$, and a postoperative infusion of $0.1 \mathrm{mg} / \mathrm{kg} / \mathrm{h}$. Postoperative opioid usage was similar between the two groups as were the reported pain scores.

4.3. Orthopedic Surgery. Cengiz et al. [43] performed a randomized double-blinded study to evaluate the effect of low-dose $(6 \mu \mathrm{g} / \mathrm{kg} /$ minute $)$ intraoperative ketamine on postoperative pain after total knee replacement surgery. The control group received a placebo. There was a prolonged time to first analgesic request in the ketamine group and a reduction in cumulative morphine consumption at 1, 3, 6, 12, and 24 hours after surgery. VAS scores were also significantly lower in the group receiving ketamine instead of placebo.

A study performed by Guará Sobrinho et al. [44] assessed ketamine's effectiveness as an analgesic agent when delivered intra-articularly during total knee replacement surgery. Authors did not find a significant difference between groups using $0.25 \mathrm{mg} / \mathrm{kg} \mathrm{S}(+)$ ketamine, $0.5 \mathrm{mg} / \mathrm{kg} \mathrm{S}(+)$ ketamine and control groups in terms of postoperative pain scores.

4.4. Thoracic Surgery. D'Alonzo et al. [45] tested a single $0.5 \mathrm{mg} / \mathrm{kg}$ bolus of ketamine delivered intravenously prior to chest wall incision versus placebo. Levels of IL-6 and C-reactive protein (CRP) were compared before and after surgery between the two groups and reported pain scores at 4 and 24 hours postoperatively. IL-6 levels, CRP levels, and postoperative pain scores at both of these times did not vary significantly between the two groups, suggesting that this dosing schedule of ketamine does not have a measurable effect on postoperative pain in thoracic surgery.

Nesher et al's 2008 study [46] examined thoracic surgery patients who received PCA boluses of morphine combined with ketamine versus morphine alone. Fifty-eight patients were divided into two groups, one group receiving $1.5 \mathrm{mg}$ IV bolus morphine upon request and the other receiving $1.0 \mathrm{mg}$ morphine and $5 \mathrm{mg}$ ketamine IV bolus upon request. The group receiving the ketamine/morphine combination required only half the amount of morphine as the morphineonly group. At the 36-hour time-point, 10 of the morphineonly patients still required PCA compared to 5 patients in the morphine/ketamine group. Pain scores and postoperative nausea and vomiting (PONV) were also decreased in the ketamine/morphine group.

4.5. Ophthalmological Surgery. Abdolahi et al. [47] utilized low-dose ketamine $(0.5 \mathrm{mg} / \mathrm{kg})$ during painful ophthalmologic surgeries (i.e., retinal detachments, strabismus, and keratoplasty). Ketamine was administered during anesthetic 


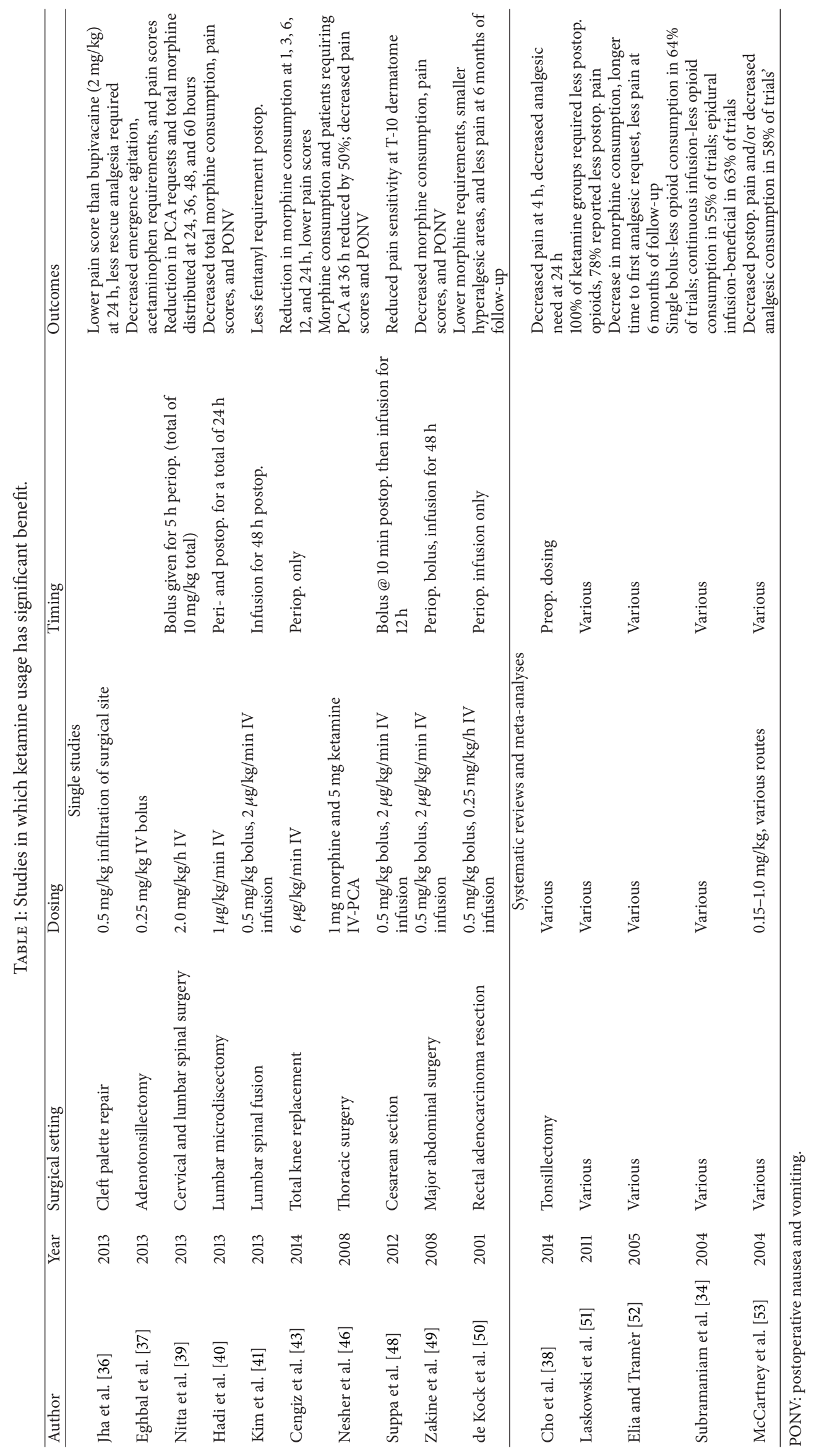


induction. Recovery time, postoperative pain scores, anesthetic consumption, analgesic requirements, and perioperative additional analgesic were measured across the two groups. There were no differences in any of these variables between the two groups.

4.6. Gynecological Surgery. Thomas et al. [54] studied the usage of a single preoperative dose of ketamine before elective gynecological procedures. This prospective study divided patients into a control group, which received normal saline and a ketamine group, which received $0.15 \mathrm{mg} / \mathrm{kg}$ of ketamine just before anesthetic induction. Although the ketamine group required slightly less cumulative morphine for postoperative analgesia, this result was not significant. There was also no significant difference in the reporting of pain on the VAS between the two groups. Although there was no difference in the length of postoperative stays, the group receiving ketamine reported significantly greater satisfaction with their pain management.

Bilgen et al's 2012 study [55] utilized three different doses of ketamine $(0.25,0.5$, and $1 \mathrm{mg} / \mathrm{kg})$ and a placebo to test the effects on postoperative morphine requirements and pain in women undergoing elective Cesarean sections. The primary outcome assessed was cumulative postoperative morphine consumption at 48 hours. This variable, acute pain score and prolonged postoperative pain measured at 2 weeks, 1 month, 6 months, and 1 year were all similar between all groups. Ketamine did not have a significant effect on any of these outcomes.

Suppa et al. [48] performed a similar study in women undergoing elective Cesarean sections, using a $0.5 \mathrm{mg} / \mathrm{kg}$ ketamine bolus 10 minutes after birth in addition to a $2 \mu \mathrm{g} / \mathrm{kg} / \mathrm{min}$ IV ketamine infusion for 12 hours thereafter. Usage of ketamine reduced morphine requirements at the $4-8,8-12$, and $12-24$-hour time points. The patients in the ketamine group showed reduced pain sensitivity at the T-10 dermatome, suggesting an antihyperalgesic effect. At three years after surgery, patients reported no differences in residual pain or dysesthetic symptoms.

4.7. Major Abdominal Surgery. Zakine et al. [49] performed a double-blinded study comparing the effectiveness of ketamine administration in two different settings with one control group which received placebo. The first ketamine group received a $0.5 \mathrm{mg} / \mathrm{kg}$ bolus perioperatively and a $2 \mu \mathrm{g} / \mathrm{kg} / \mathrm{min}$ infusion thereafter for 48 hours; the second ketamine group received a $0.5 \mathrm{mg} / \mathrm{kg}$ bolus perioperatively and a $2 \mu \mathrm{g} / \mathrm{kg} / \mathrm{min}$ infusion only for the duration of the surgical procedure. All of the patients were given morphine PCA. The authors found that cumulative morphine consumption was significantly lower in the group receiving the 48-hour infusion when compared to the shorter infusion and control groups. VAS scores were measured postoperatively and were significantly lower in the ketamine groups when compared to the control group. As an added effect, while all patients in the study received hydroxyzine preoperatively, the 48-hour infusion group experienced significantly less nausea than the control group ( $4 \%$ versus $27 \%, P=0.005$ ). It is worth nothing that there were no side effects of the ketamine, psychotomimetic, or otherwise.

Katz et al. [56] analyzed ketamine as a postoperative analgesic in men undergoing radical prostatectomy. Men were double-blinded into 3 different groups, all of which received fentanyl. In addition, group 1 received a preincisional intravenous bolus $(0.2 \mathrm{mg} / \mathrm{kg})$ and infusion $(0.0025 \mathrm{~mL} / \mathrm{kg} / \mathrm{min})$ of ketamine, group 2 received the same dosages 70 minutes after incision, and group 3 received no ketamine. The authors found that pain scores did not differ significantly among the groups and follow-up at two weeks and again at six months they showed no significant differences in pain incidence or intensity.

de Kock et al. [50] studied ketamine given both systemically and epidurally to patients undergoing rectal adenocarcinoma resection. All patients received a preoperative epidural bolus and continuous infusion of bupivacaine/ sufentanil/clonidine. A control group received no ketamine, and other groups received ketamine at different dosages, administered either epidurally or intravenously. The group that received a ketamine bolus of $0.5 \mathrm{mg} / \mathrm{kg}$ and continuous infusion of $0.25 \mathrm{mg} / \mathrm{kg} / \mathrm{h}$ had significantly lower PCA requirements, smaller hyperalgesic areas, and less residual pain through six months of follow-up.

4.8. Systematic Reviews. A 2011 review by Laskowski et al. [51] found a reduction in total opioid consumption and an increase in time to first analgesic request in groups receiving ketamine. $78 \%$ of the ketamine treatment groups required less postoperative opioid analgesia and reported less postoperative pain.

A second review by Elia and Tramèr [52] shows significant decreases in pain intensity at rest when ketamine is compared with a control at $6 \mathrm{~h}, 12 \mathrm{~h}, 24 \mathrm{~h}$, and 48 hours postoperatively. All trials except one within the review report a significant decrease in morphine consumption when ketamine is used intraoperatively. Average time to first analgesic request had an average improvement of 16 minutes. Regarding long-term follow-up, significantly fewer patients who had received high-dose IV ketamine (bolus $0.5 \mathrm{mg} / \mathrm{kg}$, infusion $0.25 \mathrm{mg} / \mathrm{kg} / \mathrm{h}$ during surgery) suffered from residual pain at the 6-month mark.

Subramaniam et al.s 2004 systematic review [34], including 37 studies and 2385 patients, addressed ketamine's effectiveness in reducing opioid consumption for postoperative analgesia. They divided subjects into 4 subgroups based on the route and method of ketamine administration: ketamine as single dose, continuous infusion, PCA, and epidural ketamine with opioids. Low-dose ketamine was found to be safe, and no increase in side effects was suggested. A single bolus dose of ketamine decreased opioid requirements in 7 of 11 studies. Continuous infusion of ketamine decreased IV and epidural opioid requirements in 6 out of 11 studies. Adding ketamine to PCA morphine was not found to be useful. Epidural ketamine showed beneficial effects in 5 out of 8 studies. Among the various methods of IV ketamine administration, continuous IV infusion of ketamine was the most helpful in major surgeries requiring increased postoperative 
opiate use such as major abdominal surgical procedures and thoracic procedures.

McCartney et al. [53] performed a systematic review that looked at the effects of various NMDA receptor antagonists, including ketamine, on postoperative pain and analgesic consumption. Twenty-four ketamine-based studies met their inclusion criteria; 14 of 24 (58\%) demonstrated a positive effect in lowering postoperative pain and/or decreasing analgesic consumption. Dosages used in the analyzed studies ranged from 0.15 to $1 \mathrm{mg} / \mathrm{kg}$.

\section{Adverse Effects}

Ketamine has been reported to be a safe and well-tolerated drug $[57,58]$. Despite the benefits and the increase in popularity of using ketamine as both an anesthetic and an analgesic, there are some troubling adverse effects associated with its use. These effects are usually temporary; however, they can be significantly distressing for patients. Therefore, it is paramount to discuss these effects. Common adverse effects include feelings of inebriation, nausea, psychotomimetic effects, and headaches with long-term use, possibly resulting in impaired cognition, memory, and mood [10].

The most common concerns about ketamine as an analgesic agent are related to its mind-altering effects. Katalinic's team addressed these concerns and their review showed that most of the research conducted using subanesthetic doses of ketamine has shown transient increases in the following psychiatric symptoms: positive and negative symptoms of schizophrenia, dissociative symptoms, and manic symptoms. Fortuitously, these symptoms are only present at times of administration and usually disappear within 60 minutes of administration [19]. Quiet, relaxed surroundings contribute to a reduced incidence of these side effects and when ketamine is administered alone, the prophylactic use of a sedative agent such as $3.75-7.5 \mathrm{mg}$ oral midazolam has generally decreased their incidence and severity [4].

Other psychotomimetic effects of ketamine use include feelings of intoxication, increased confusion, lowered inhibition, and perceptual disturbances. In addition, research shows that chronic use of ketamine may impair several memory systems including episodic and working memory. Nonetheless, these effects have been restricted to time of administration and are transient in nature. Additionally, implications of these effects have not been found to be dependent on dose or route of administration [19].

No severe physical symptoms have been reported with the use of low-dose ketamine; however, studies have reported benign effects of lightheadedness, headache, nausea, diplopia, drowsiness, and dizziness. These effects, unlike the psychotomimetic effects, tend to be dose-dependent. They are also limited to time of administration and a short time thereafter [19].

Ketamine can also induce various CNS side effects (e.g., dizziness, diplopia, dysphoria, dreams, hallucinations, disorientation, strange sensations, lightheadedness, sleep difficulties, and confusion). One systematic review found incidences of these CNS effects were $18 \%, 10 \%, 9 \%$, and $0.7 \%$ with
IV PCA, IV infusion, IV single dose, and epidural groups, respectively. No significant increase in these effects was seen compared to patients who did not receive ketamine [34].

Almost 200 cases of ketamine-induced uropathy have been reported in the literature, mostly in the context of chronic abuse, but five within medical analgesic use [19]. Case series demonstrate a temporal link between ketamine abuse and urological symptoms, urinary tract damage, and renal impairment, with some but not all symptoms improving upon cessation of ketamine. Chu et al. reported lower urinary tract symptoms of ketamine-induced cystitis, dysuria, urgency, frequency, incontinence, macroscopic hematuria, and suprapubic pain. Investigations showed negative urine cultures in $97 \%$ and cystoscopy showed epithelial damage in $71 \%$ [59].

Hepatotoxicity has been reported at anesthetic doses $(\geq 1 \mathrm{mg} / \mathrm{kg}$ ) and patients receiving low-dose continuous infusion. Noppers et al. present data on the occurrence of ketamine-induced liver injury during repeated administrations of $\mathrm{S}(+)$ ketamine for the treatment of chronic pain. Six patients received 2 continuous intravenous 100-hour $\mathrm{S}(+)$ ketamine infusions, $10-20 \mathrm{mg} / \mathrm{h}$, separated by 16 days. Three of these patients developed hepatotoxicity evident through elevated transaminases. Ketamine infusion was promptly terminated and the liver enzymes slowly returned to reference values within 2 months, suggesting an increased risk for development of ketamine-induced liver injury when the infusion is prolonged and/or repeated within a short time frame [60]. Trials using single doses of ketamine $<1 \mathrm{mg} / \mathrm{kg}$ report no changes in liver function tests [19].

It has been described in the literature that ketamine use can lead to neuronal cell apoptosis. This is triggered by the direct blockade of NMDA receptors. The effect was demonstrated in rats at repeated doses of $20 \mathrm{mg} / \mathrm{kg}$ [61]. However, an effect was not seen after a single bolus at this dose [62]. This is especially concerning in the developing brain, where ketamine can interfere with both neuronal proliferation and differentiation [63]. Recent studies have already indicated that ketamine can result in long-lasting cognitive deficits in a primate model. Paule et al. tested this effect with rhesus monkeys who received enough ketamine to maintain anesthesia for a 24 hour surgery during their first week of life. At approximately 10 months of age, control monkeys began to outperform the ketamine-dosed monkeys at a battery of tests. At three-and-one-half years of age, the ketamine monkeys still performed worse than the controls [64].

Chang et al. [65] reported a marked and sudden increase in intracranial pressure (ICP) during induction with ketamine in a patient with traumatic brain injury. It should be noted, however, that this patient's ICP was quite elevated even before induction. The ICP fell rapidly when mechanical ventilation began. Administration of ketamine for sedations has been shown to result in higher opening pressures during lumbar puncture in children, but this effect, like the psychotomimetic effects, can be tempered with midazolam [66].

In a study conducted to evaluate the safety and efficacy of ketamine for the treatment of refractory status epilepticus, 
it was found that the drug's administration caused possible adverse events in 5 out of 60 study patients. These included a life-threatening severe acidosis, a syndrome similar to propofol-related infusion syndrome, supraventricular tachycardia, and atrial fibrillation [67].

Ketamine is not FDA-approved for epidural use as it carries a risk of neurotoxicity. Furthermore, there is no safety or efficacy data on the neuraxial administration of ketamine. Because of this, the epidural and/or intrathecal administration of ketamine are discouraged outside of the preclinical research setting. Spinal neurotoxicity after continuous intrathecal ketamine infusion of $5 \mathrm{mg}$ /day over 3 weeks has been reported [68]. However, the drug used in this case was not preservative-free, and chemical cytotoxicity has often implicated the preservatives used rather than the active compound. Therefore, only preservative-free ketamine should be used for intrathecal infusion. This effect was also described after a 3-week continuous infusion, a situation that we are unlikely to see in patients that are given ketamine with the short-term goal of postoperative analgesia.

Potential dependence through chronic or repetitive ketamine use is concerning. Studies of recreation ketamineusing populations report cravings for the drug, physiological tolerance, and possible withdrawal symptoms on drug cessation. Physiological tolerance is of particular relevance as it has been suggested for individuals having undergone repeated procedures requiring anesthesia with ketamine [19]. Tolerance development with ketamine used as analgesia is less certain. Perry et al. [69] followed healthy subjects given subanesthetic doses of ketamine for up to 6 months. Results showed no reports of cravings or abuse outside of the study, suggesting that ketamine in low doses is less likely to produce dependence.

\section{Conclusion}

Although it was first used purely as an anesthetic, ketamine is making a certain resurgence in the management of postoperative pain. Many of the aforementioned studies have demonstrated significant effectiveness in controlling postoperative pain, increasing time to first analgesic request, and decreasing overall opioids required, as well as demonstrating fewer of the opioid-related side effects like PONV. These effects have been demonstrated across many realms of surgery, including otolaryngology, abdominal surgery, orthopedic surgery, spinal surgery, and gynecological surgery. While all of the exact mechanisms have not been entirely agreed upon, the primary effect of the drug is related to its NMDA receptor antagonism. An intravenous bolus given prior to incision followed by a continuous infusion appears to be the most effective modality for postoperative pain control. If the infusion is given over a protracted time course $(48 \mathrm{~h})$ for more invasive and routinely painful procedures, patients can have a decreased risk of developing persistent postoperative pain in months that follow. This infusion can also be combined with PCA for excellent control of acute postoperative pain. Ketamine may not provide a clear benefit for patients undergoing smaller procedures, as analgesia with low dosages of opioids,
NSAIDs, and local anesthetic infiltration can usually provide adequate pain relief. The often feared psychotomimetic effects can be blunted by administering general anesthesia or the less effective benzodiazepine. While animal models show some degree of neurotoxicity in high-dose applications and possible induction of neuronal apoptosis, these effects have not been demonstrated and are not of concern at the dosages and durations employed for postoperative analgesia. The other conclusion that can be drawn from the aforementioned studies is that although ketamine was effective in many of the trials, other trials showed that it provided no benefit when compared to a placebo. While ketamine holds a place in the prevention and treatment of postoperative pain, more large, high-quality controlled studies are necessary in order to determine which procedures it is best suited for and at what dosages and frequencies it should be administered.

\section{Conflict of Interests}

The authors declare no competing financial interests.

\section{Acknowledgment}

All research performed by Department of Anesthesiology, Rutgers New Jersey Medical School.

\section{References}

[1] A. Johansen, L. Romundstad, C. S. Nielsen, H. Schirmer, and A. Stubhaug, "Persistent postsurgical pain in a general population: prevalence and predictors in the Tromso study," Pain, vol. 153, no. 7, pp. 1390-1396, 2012.

[2] A. Meera, "Pain and opioid dependence: is it a matter of concern," Indian Journal of Palliative Care, vol. 17, no. 4, pp. S36S38, 2011.

[3] M. Suzuki, "Role of N-methyl-D-aspartate receptor antagonists in postoperative pain management," Current Opinion in Anaesthesiology, vol. 22, no. 5, pp. 618-622, 2009.

[4] S. Himmelseher and M. E. Durieux, "Ketamine for perioperative pain management," Anesthesiology, vol. 102, no. 1, pp. 211220, 2005.

[5] E. F. Domino, P. Chodoff, and G. Corssen, "Pharmacologic effects of CI-581, a new dissociative anesthetic, in man," Clinical Pharmacology and Therapeutics, vol. 6, pp. 279-291, 1965.

[6] F. Aroni, N. Iacovidou, I. Dontas, C. Pourzitaki, and T. Xanthos, "Pharmacological aspects and potential new clinical applications of ketamine: reevaluation of an old drug," Journal of Clinical Pharmacology, vol. 49, no. 8, pp. 957-964, 2009.

[7] J. Persson, "Ketamine in pain management," CNS Neuroscience \& Therapeutics, vol. 19, no. 6, pp. 396-402, 2013.

[8] M. Naughton, G. Clarke, O. F. O’Leary, J. F. Cryan, and T. G. Dinan, "A review of ketamine in affective disorders: current evidence of clinical efficacy, limitations of use and preclinical evidence on proposed mechanisms of action," Journal of Affective Disorders, vol. 156, pp. 24-35, 2014.

[9] K. A. B. Lapidus, C. F. Levitch, A. M. Perez et al., "A randomized controlled trial of intranasal ketamine in major depressive disorder," Biological Psychiatry, vol. 76, no. 12, pp. 970-976, 2014.

[10] P. Azari, D. R. Lindsay, D. Briones, C. Clarke, T. Buchheit, and S. Pyati, "Efficacy and safety of ketamine in patients with complex 
regional pain syndrome: a systematic review, CNS Drugs, vol. 26, no. 3, pp. 215-228, 2012.

[11] R. F. Bell, C. Eccleston, and E. A. Kalso, "Ketamine as an adjuvant to opioids for cancer pain," The Cochrane Database of Systematic Reviews, no. 11, Article ID CD003351, 2012.

[12] W. Leppert, "Ketamine in the management of cancer pain," Journal of Clinical Oncology, vol. 31, no. 10, article 1374, 2013.

[13] J. H. Krystal, S. Madonick, E. Perry et al., "Potentiation of low dose ketamine effects by naltrexone: potential implications for the pharmacotherapy of alcoholism," Neuropsychopharmacology, vol. 31, no. 8, pp. 1793-1800, 2006.

[14] E. Krupitsky, A. Burakov, T. Romanova, I. Dunaevsky, R. Strassman, and A. Grinenko, "Ketamine psychotherapy for heroin addiction: immediate effects and two-year follow-up," Journal of Substance Abuse Treatment, vol. 23, no. 4, pp. 273283, 2002.

[15] E. M. Krupitsky, A. M. Burakov, I. V. Dunaevsky, T. N. Romanova, T. Y. Slavina, and A. Y. Grinenko, "Single versus repeated sessions of ketamine-assisted psychotherapy for people with heroin dependence," Journal of Psychoactive Drugs, vol. 39, no. 1, pp. 13-19, 2007.

[16] K. R. Jat and D. Chawla, "Ketamine for management of acute exacerbations of asthma in children," The Cochrane Database of Systematic Reviews, vol. 11, Article ID CD009293, 2012.

[17] K. R. Jat, C. Azad, and V. Guglani, "Use of ketamine for refractory wheezing in an infant," Indian Pediatrics, vol. 49, no. 7, pp. 587-588, 2012.

[18] M. Wang, Q. Wang, Y. Y. Yu, and W. S. Wang, "An effective dose of ketamine for eliminating pain during injection of propofol: a dose response study," Annales Francaises d'Anesthesie et de Reanimation, vol. 32, no. 9, pp. e103-e106, 2013.

[19] N. Katalinic, R. Lai, A. Somogyi, P. B. Mitchell, P. Glue, and C. K. Loo, "Ketamine as a new treatment for depression: a review of its efficacy and adverse effects," The Australian and New Zealand Journal of Psychiatry, vol. 47, no. 8, pp. 710-727, 2013.

[20] I. Oye, O. Paulsen, and A. Maurset, "Effects of ketamine on sensory perception: evidence for a role of N-methyl-Daspartate receptors," Journal of Pharmacology and Experimental Therapeutics, vol. 260, no. 3, pp. 1209-1213, 1992.

[21] G. Mion and T. Villevieille, "Ketamine pharmacology: an update (pharmacodynamics and molecular aspects, recent findings)," CNS Neuroscience \& Therapeutics, vol. 19, no. 6, pp. 370380, 2013.

[22] J. A. Clements, W. S. Nimmo, and I. S. Grant, "Bioavailability, pharmacokinetics, and analgesic activity of ketamine in humans," Journal of Pharmaceutical Sciences, vol. 71, no. 5, pp. 539-542, 1982.

[23] I. S. Grant, W. S. Nimmo, L. R. McNicol, and J. A. Clements, "Ketamine disposition in children and adults," British Journal of Anaesthesia, vol. 55, no. 11, pp. 1107-1111, 1983.

[24] C. J. Woolf and S. W. N. Thompson, "The induction and maintenance of central sensitization is dependent on N-methyl-Daspartic acid receptor activation; implications for the treatment of post-injury pain hypersensitivity states," Pain, vol. 44, no. 3 , pp. 293-299, 1991.

[25] L. A. Rosseland, A. Stubhaug, L. Sandberg, and H. Breivik, "Intra-articular (IA) catheter administration of postoperative analgesics. A new trial design allows evaluation of baseline pain, demonstrates large variation in need of analgesics, and finds no analgesic effect of IA ketamine compared with IA saline," Pain, vol. 104, no. 1-2, pp. 25-34, 2003.
[26] M. Niesters, N. Khalili-Mahani, C. Martini et al., "Effect of subanesthetic ketamine on intrinsic functional brain connectivity: a placebo-controlled functional magnetic resonance imaging study in healthy male volunteers," Anesthesiology, vol. 117, no. 4, pp. 868-877, 2012.

[27] R. Rogers, R. G. Wise, D. J. Painter, S. E. Longe, and I. Tracey, "An investigation to dissociate the analgesic and anesthetic properties of ketamine using functional magnetic resonance imaging," Anesthesiology, vol. 100, no. 2, pp. 292-301, 2004.

[28] D. J. Smith, R. L. Bouchal, C. A. DeSanctis et al., "Properties of the interaction between ketamine and opiate binding sites in vivo and in vitro," Neuropharmacology, vol. 26, no. 9, pp. 12531260, 1987.

[29] O. Hustveit, A. Maurset, and I. Oye, "Interaction of the chiral forms of ketamine with opioid, phencyclidine, sigma and muscarinic receptors," Pharmacology \& Toxicology, vol. 77, no. 6, pp. 355-359, 1995.

[30] A. Maurset, L. A. Skoglund, O. Hustveit, and I. Øye, "Comparison of ketamine and pethidine in experimental and postoperative pain," Pain, vol. 36, no. 1, pp. 37-41, 1989.

[31] L. Stella, A. Crescenti, and G. Torri, "Effect of naloxone on the loss of consciousness induced by I.V. anaesthetic agents in man," British Journal of Anaesthesia, vol. 56, no. 4, pp. 369-373, 1984.

[32] D. D. F. Pacheco, T. R. L. Romero, and I. D. G. Duarte, "Central antinociception induced by ketamine is mediated by endogenous opioids and $\mu$ - And $\delta$-opioid receptors," Brain Research, vol. 1562, pp. 69-75, 2014.

[33] A. de Bartolomeis, C. Sarappa, E. F. Buonaguro et al., "Different effects of the NMDA receptor antagonists ketamine, MK-801, and memantine on postsynaptic density transcripts and their topography: role of Homer signaling, and implications for novel antipsychotic and pro-cognitive targets in psychosis," Progress in Neuro-Psychopharmacology and Biological Psychiatry, vol. 46, pp. 1-12, 2013.

[34] K. Subramaniam, B. Subramaniam, and R. A. Steinbrook, "Ketamine as adjuvant analgesic to opioids: a quantitative and qualitative systematic review," Anesthesia and Analgesia, vol. 99, no. 2, pp. 482-495, 2004.

[35] P. Lavand'homme, M. De Kock, and H. Waterloos, "Intraoperative epidural analgesia combined with ketamine provides effective preventive analgesia in patients undergoing major digestive surgery," Anesthesiology, vol. 103, no. 4, pp. 813-820, 2005.

[36] A. K. Jha, N. Bhardwaj, S. Yaddanapudi, R. K. Sharma, and J. K. Mahajan, "A randomized study of surgical site infiltration with bupivacaine or ketamine for pain relief in children following cleft palate repair," Paediatric Anaesthesia, vol. 23, no. 5, pp. 401406, 2013.

[37] M. H. Eghbal, S. Taregh, A. Amin, and M. A. Sahmeddini, "Ketamine improves postoperative pain and emergence agitation following adenotonsillectomy in children. A randomized clinical trial," Middle East Journal of Anesthesiology, vol. 22, no. 2, pp. 155-160, 2013.

[38] H. K. Cho, K. W. Kim, Y. M. Jeong, H. S. Lee, Y. J. Lee, and S. H. Hwang, "Efficacy of ketamine in improving pain after tonsillectomy in children: meta-analysis," PLOS ONE, vol. 9, no. 6, Article ID e101259, 2014.

[39] R. Nitta, T. Goyagi, and T. Nishikawa, "Combination of oral clonidine and intravenous low-dose ketamine reduces the consumption of postoperative patient-controlled analgesia morphine after spine surgery," Acta Anaesthesiologica Taiwanica, vol. 51, no. 1, pp. 14-17, 2013. 
[40] B. A. Hadi, R. Daas, and R. Zelkó, "A randomized, controlled trial of a clinical pharmacist intervention in microdiscectomy surgery-low dose intravenous ketamine as an adjunct to standard therapy," Saudi Pharmaceutical Journal, vol. 21, no. 2, pp. 169-175, 2013.

[41] S. H. Kim, S. I. Kim, S. Y. Ok et al., "Opioid sparing effect of low dose ketamine in patients with intravenous patient-controlled analgesia using fentanyl after lumbar spinal fusion surgery," Korean Journal of Anesthesiology, vol. 64, no. 6, pp. 524-528, 2013.

[42] S. R. Pestieau, J. C. Finkel, M. M. Junqueira et al., "Prolonged perioperative infusion of low-dose ketamine does not alter opioid use after pediatric scoliosis surgery," Paediatric Anaesthesia, vol. 24, no. 6, pp. 582-590, 2014.

[43] P. Cengiz, D. Gokcinar, I. Karabeyoglu, H. Topcu, G. S. Cicek, and N. Gogus, "Intraoperative low-dose ketamine infusion reduces acute postoperative pain following total knee replacement surgery: a prospective, randomized double-blind placebo-controlled trial," Journal of the College of Physicians and Surgeons-Pakistan, vol. 24, no. 5, pp. 299-303, 2014.

[44] H. Guará Sobrinho, J. B. S. Garcia, J. W. Vasconcelos, J. C. A. Sousa, and L. S. G. Ferro, "Analgesic efficacy of the intraarticular administration of $S(+)$ - ketamine in patients undergoing total knee arthroplasty," Revista Brasileira de Anestesiologia, vol. 62 , no. 5, pp. 665-675, 2012.

[45] R. C. D’Alonzo, E. Bennett-Guerrero, M. Podgoreanu, T. A. D'Amico, D. H. Harpole, and A. D. Shaw, "A randomized, double blind, placebo controlled clinical trial of the preoperative use of ketamine for reducing inflammation and pain after thoracic surgery," Journal of Anesthesia, vol. 25, no. 5, pp. 672-678, 2011.

[46] N. Nesher, I. Serovian, N. Marouani, S. Chazan, and A. A. Weinbroum, "Ketamine spares morphine consumption after transthoracic lung and heart surgery without adverse hemodynamic effects," Pharmacological Research, vol. 58, no. 1, pp. 3844, 2008.

[47] M. Abdolahi, H. A. Soltani, K. Montazeri, and B. Soleymani, "Preemptive low-dose of ketamine does not effective on anesthetic consumption, perioperative analgesic requirement and postoperative pain, nausea and vomiting in painful ophthalmic surgery," Journal of Research in Medical Sciences, vol. 18, pp. 583587, 2013.

[48] E. Suppa, A. Valente, S. Catarci, B. A. Zanfini, and G. Draisci, "A study of low-dose S-ketamine infusion as 'preventive' pain treatment for cesarean section with spinal anesthesia: benefits and side effects," Minerva Anestesiologica, vol. 78, no. 7, pp. 774781, 2012.

[49] J. Zakine, D. Samarcq, E. Lorne et al., "Postoperative ketamine administration decreases morphine consumption in major abdominal surgery: a prospective, randomized, double-blind, controlled study," Anesthesia \& Analgesia, vol. 106, no. 6, pp. 1856-1861, 2008.

[50] M. de Kock, P. Lavand'homme, and H. Waterloos, “'Balanced analgesia' in the perioperative period: Is there a place for ketamine?” Pain, vol. 92, no. 3, pp. 373-380, 2001.

[51] K. Laskowski, A. Stirling, W. P. McKay, and H. J. Lim, “A systematic review of intravenous ketamine for postoperative analgesia," Canadian Journal of Anesthesia, vol. 58, no. 10, pp. 911-923, 2011.

[52] N. Elia and M. R. Tramèr, "Ketamine and postoperative pain-a quantitative systematic review of randomised trials," Pain, vol. 113, no. 1-2, pp. 61-70, 2005.
[53] C. J. L. McCartney, A. Sinha, and J. Katz, "A qualitative systematic review of the role of N-methyl-D-aspartate receptor antagonists in preventive analgesia," Anesthesia \& Analgesia, vol. 98, no. 5, pp. 1385-1400, 2004.

[54] M. Thomas, I. Tennant, R. Augier, G. Gordon-Strachan, and H. Harding, "The role of pre-induction ketamine in the management of postoperative pain in patients undergoing elective gynaecological surgery at the University Hospital of the West Indies," The West Indian Medical Journal, vol. 61, pp. 224-229, 2012.

[55] S. Bilgen, Ö. Köner, H. Türe, F. Menda, C. Fiçicioğlu, and B. Aykaç, "Effect of three different doses of ketamine prior to general anaesthesia on postoperative pain following caesarean delivery: a prospective randomized study," Minerva Anestesiologica, vol. 78, no. 4, pp. 442-449, 2012.

[56] J. Katz, R. Schmid, D. G. Snijdelaar, T. J. Coderre, C. J. L. McCartney, and A. Wowk, "Pre-emptive analgesia using intravenous fentanyl plus low-dose ketamine for radical prostatectomy under general anesthesia does not produce short-term or long-term reductions in pain or analgesic use," Pain, vol. 110, no. 3, pp. 707-718, 2004.

[57] C. J. A. Morgan and H. V. Curran, "Ketamine use: a review," Addiction, vol. 107, no. 1, pp. 27-38, 2012.

[58] R. J. Strayer and L. S. Nelson, "Adverse events associated with ketamine for procedural sedation in adults," The American journal of emergency medicine, vol. 26, no. 9, pp. 985-1028, 2008.

[59] H. S. Smith, "Ketamine-induced urologic insult (KIUI)," Pain Physician, vol. 13, no. 6, pp. E343-E346, 2010.

[60] I. M. Noppers, M. Niesters, L. P. H. J. Aarts et al., "Drug-induced liver injury following a repeated course of ketamine treatment for chronic pain in CRPS type 1 patients: a report of 3 cases," Pain, vol. 152, no. 9, pp. 2173-2178, 2011.

[61] A. C. Scallet, L. C. Schmued, W. Slikker Jr. et al., "Developmental neurotoxicity of ketamine: morphometric confirmation, exposure parameters, and multiple fluorescent labeling of apoptotic neurons," Toxicological Sciences, vol. 81, no. 2, pp. 364-370, 2004.

[62] V. Jevtovic-Todorovic, D. F. Wozniak, N. D. Benshoff, and J. W. Olney, "A comparative evaluation of the neurotoxic properties of ketamine and nitrous oxide," Brain Research, vol. 895, no. 1-2, pp. 264-267, 2001.

[63] C. Dong and K. J. S. Anand, "Developmental neurotoxicity of ketamine in pediatric clinical use," Toxicology Letters, vol. 220, no. 1, pp. 53-60, 2013.

[64] M. G. Paule, M. Li, R. R. Allen et al., "Ketamine anesthesia during the first week of life can cause long-lasting cognitive deficits in rhesus monkeys," Neurotoxicology and Teratology, vol. 33, no. 2, pp. 220-230, 2011.

[65] L. C. Chang, S. R. Raty, J. Ortiz, N. S. Bailard, and S. J. Mathew, "The emerging use of ketamine for anesthesia and sedation in traumatic brain injuries," CNS Neuroscience \& Therapeutics, vol. 19, no. 6, pp. 390-395, 2013.

[66] K. Michalczyk, J. E. Sullivan, and J. W. Berkenbosch, "Pretreatment with midazolam blunts the rise in intracranial pressure associated with ketamine sedation for lumbar puncture in children," Pediatric Critical Care Medicine, vol. 14, no. 3, pp. el49-e155, 2013.

[67] N. Gaspard, B. Foreman, L. M. Judd et al., "Intravenous ketamine for the treatment of refractory status epilepticus: a retrospective multicenter study," Epilepsia, vol. 54, no. 8, pp. 1498-1503, 2013. 
[68] N. Karpinski, J. Dunn, L. Hansen, and E. Masliah, "Subpial vacuolar myelopathy after intrathecal ketamine: report of a case," Pain, vol. 73, no. 1, pp. 103-105, 1997.

[69] E. B. Perry Jr., J. A. Cramer, H.-S. Cho et al., "Psychiatric safety of ketamine in psychopharmacology research," Psychopharmacology, vol. 192, no. 2, pp. 253-260, 2007. 


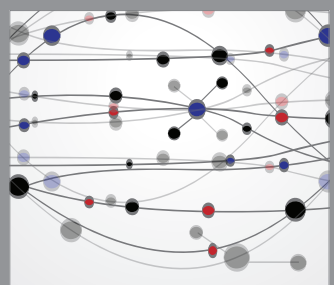

The Scientific World Journal
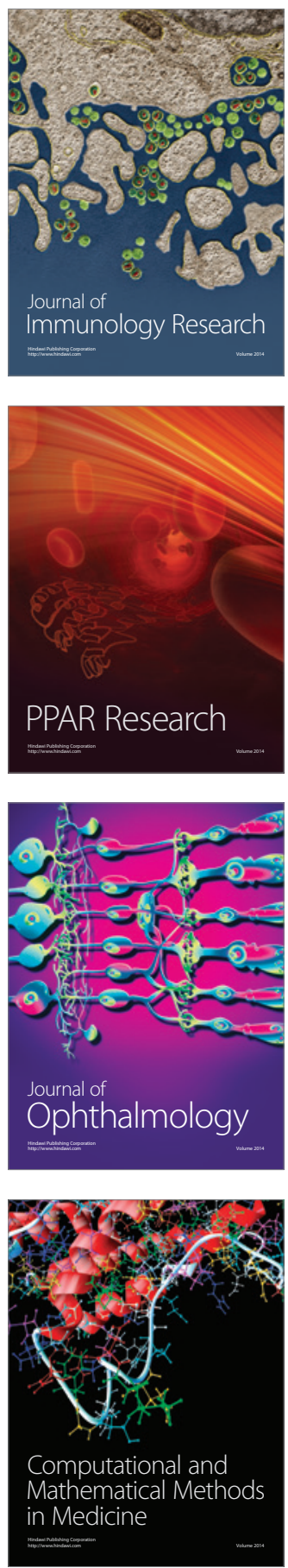

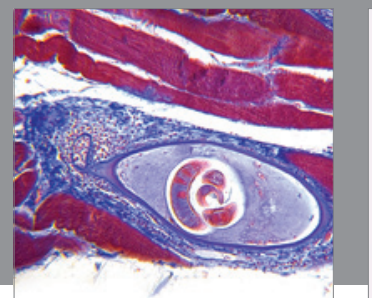

Gastroenterology

Research and Practice
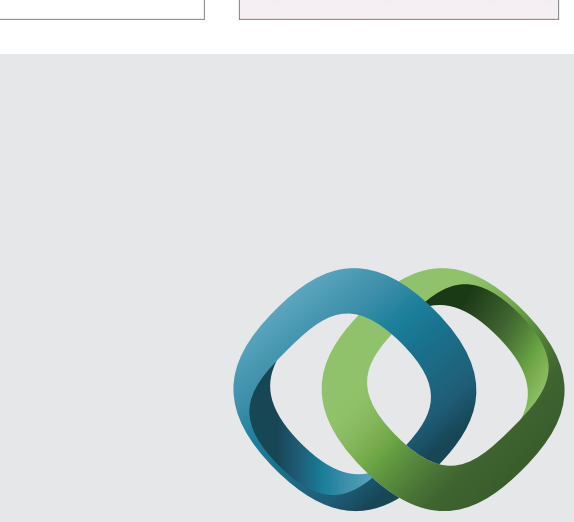

\section{Hindawi}

Submit your manuscripts at

http://www.hindawi.com
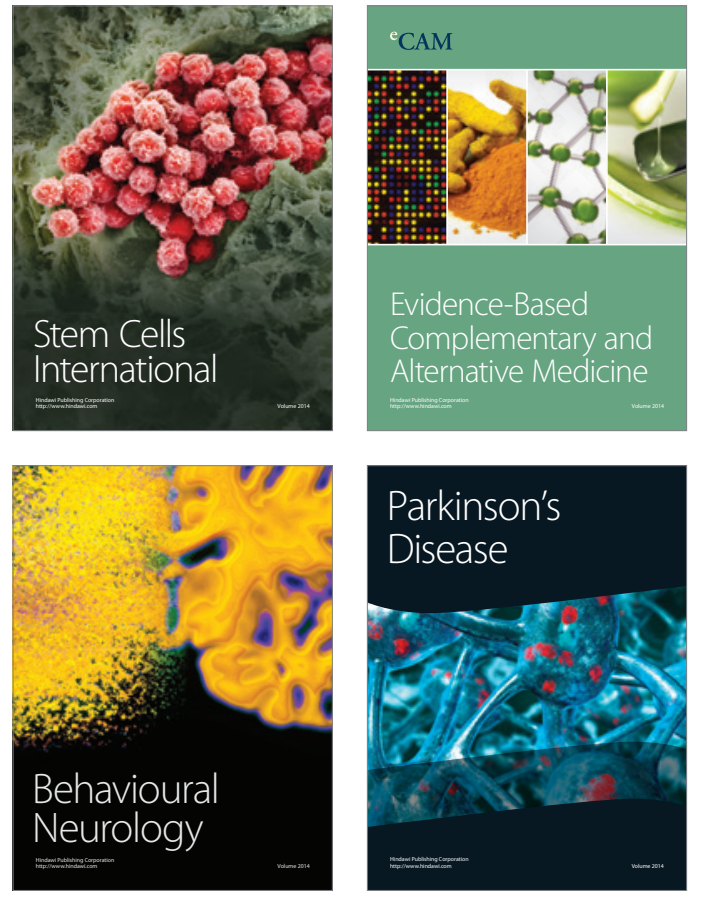
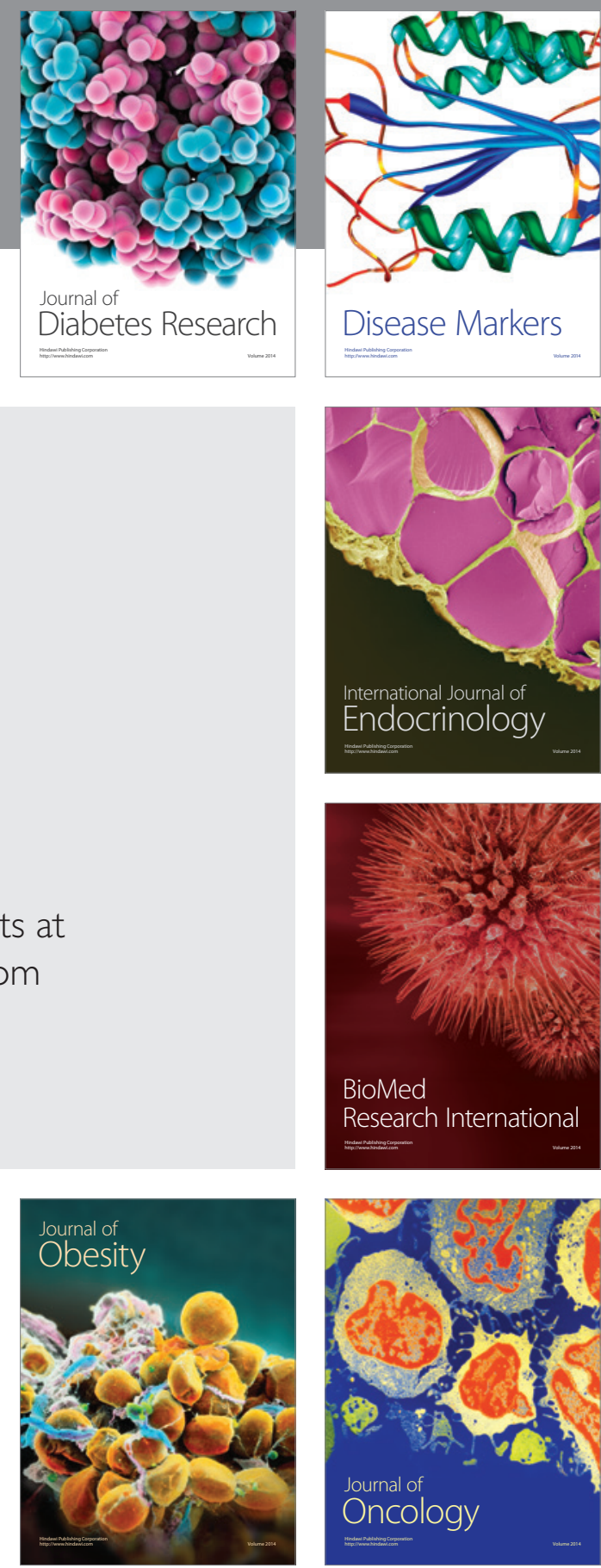

Disease Markers
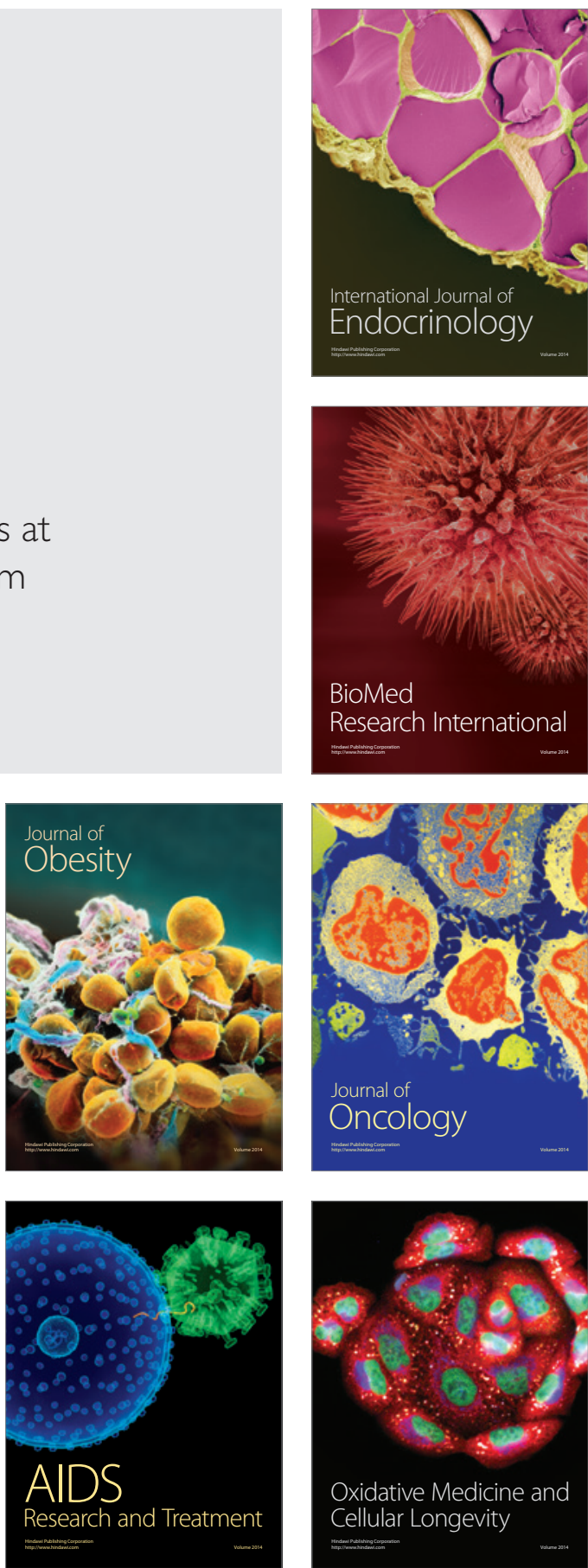